\title{
Social Psychology and Performative Interventions in Human Systems. The GENERATIVE Method
}

\author{
${ }^{1}$ Alessio Nencini, ${ }^{2}$ Alessandro Meneghini and ${ }^{3}$ Marco Prati \\ ${ }^{1}$ University of Verona, Italy \\ ${ }^{2}$ University of Padova, Italy \\ ${ }^{3}$ CFI-Multicultural Organizational Psychology, Italy
}

Article history

Received: 17-03-2015

Revised: 11-05-2015

Accepted: 12-05-2015

Corresponding Author:

Alessio Nencini

University of Verona, Italy

Tel: +390458028602

Fax: +390458028456

Email: alessio.nencini@univr.it

\begin{abstract}
The purpose of this paper is to describe the GENERATIVE method, a methodology for promoting change in human systems (i.e., contexts involving human interactions, such as organizations, communities, institutions). The first part of the paper is focused on the description of the interactionist and constructionist epistemological background adopted. The second is dedicated to the presentation of human systems as socially constructed realities. The third part is dedicated to the description of the three recursive steps of the GENERATIVE methodology: The system analysis, the negotiation and redefinition of goals and the pragmatic intervention. Finally, the presentation of the methodological steps is critically discussed in order to show how this methodology is particularly useful and effective in promoting change in human systems. The paper aims to provide insights and guidelines to professionals, practitioners and consultants working in contexts involving human interactions.
\end{abstract}

Keywords: Social Constructionism, Organizational Structure, Change Agents, Management Consulting, Quali-Quantitative Methodology

\section{Introduction}

The aim of the present paper is to propose and describe in depth the GENERATIVE method (GENERATIVE methodology for performative intervention in human systems), a methodology of intervention in contexts involving human interactions (organizations, institutions and communities), developed within a theoretical framework inspired by Symbolic Interactionism and Social Constructionism (Burr, 1998; Gergen, 1999; 2009). The main focus will be on the formulation of a methodological proposal and its connections to the epistemological background.

This paper is developed around three key concepts: The first is "shared forms of meaning", to be intended as a set of meanings, values and practices which dynamically generate-and are generated by-the human system. The second is "human system", with which we intend a system composed by people interacting in the framework of a set of common and (at least partially) institutionalized goals, providing meaning to it. The third concept is the role of whom promotes and facilitates the connection and the continuous interaction among different forms of meaning that constitute a human system, that is the "change facilitator": We use this label, instead of, for example, consultant, or practitioner, because we want to stress the broader field of application of this role, who can not only intervene in the field of consultancy to organizations, but also in other forms of human systems.

\section{Epistemological and Theoretical Background}

The theoretical background of the present paper is rooted in Symbolic Interactionism (Blumer, 1969; Mead, 1934) and Social Constructionism (Gergen, 1973; 1999; 2011).

The core of the interactionist approach poses meaning as the by-product of human interactions (Mead, 1934). According to Blumer (1969), human beings act toward social phenomena on the basis of the meaning it assumes for them. Meaning is handled and modified through an interpretative process used by the person in dealing with the things he/she encounters (Blumer, 1969). In other words, all human reality, at least in the universe of symbols and meaning, is generated by the interaction between individuals (Berger and Luckmann, 1967). More specifically, when 
we talk about social interaction, we are not referring exclusively to interpersonal exchanges: Meaning emerges as a result of wider and transversal constructions, which can be found in societal dynamics (Doise and Mapstone, 1986; Wagner and László, 2003) that provide a common ground of knowledge, "a set of meanings that are mutually known, believed, presupposed, or taken for granted by the participants of a joint activity" (Kashima, 2014).

Gergen's social constructionism criticises the prominent role that the individual mind has in human sciences and in culture (Gergen, 1997; 1999), which has brought, at least in psychology, to unfruitful attempts to control, predict and assess the "real" reality of individuals. On the contrary, heavily based on symbolic interactionism, social constructionism poses that human reality is neither objective nor universal but rather a social construction and that it is only in relationship with others that an individual exists (Gergen, 2009; 2011): Language and dialogue are the core of the process of meaning generation that characterizes human beings (Kegan and Lahey, 2001).

These assumptions have great impact on the way we propose to approach organizations and human relationships. Following the social constructionist approach, institutions, communities and organizations can be conceived as human products designed to fulfil specific social and cultural needs expressed by groups of people (Berger and Luckmann, 1967). We use the label "human system" to refer to all those systems composed and constructed by people interacting. Thus, what a human system is, in terms of the meaning deeply woven into the specific human system, is generated by the interaction among its members. In other words, it is constructed through the way in which individuals talk and act referring to it, whether it is an organization, a community, an association or an institution (Gergen et al., 2004; Gergen and Thatchenkery, 2004). For example, in the organizational context, even individual action is not to be considered as the result of the individual information processing, but as inherently social, deriving from shared meanings (Sugiman et al., 2008). The change facilitator articulates his methodological choices adopting the described epistemological background and according to the conception of human system: For example, concepts as validity and reliability, which are common criteria to assess the integrity of research in positivist research (Johnson and Cassell, 2001), lose their universal power of explanation. Instead, they can be adopted for their situated implication (Henwood and Pidgeon, 1992), so that the change facilitator, rather than being concerned with finding general laws of the human system reality, may focus on the processes of meaning construction that contextually generate that peculiar organizational reality (Gergen, 1999; Johnson and Cassell, 2001). Since organizations are not objective realities but symbolic units to which people give and share meaning, "problems"-and the way people act towards them-are also not objective or "within individuals" (as more or less stable characteristics and capacities), but rather they are the product of dysfunctional relational attempts to adapt to specific inter-personal and cultural contexts (Gergen and Thatchenkery, 2004; Perren and Grant, 2000).

\section{Presentation of the GENERATIVE Method: Theoretical Background}

The theoretical model that sustains our methodological proposal describes the construction of the meaning of a human system. It is widely based on other theoretical proposals (Contarello et al., 2009; Flick, 1998) that have been adapted in order to shape it according to the epistemological background. Graphically, the model can be represented adapting a visual form initially proposed by Flick (2000). This representation can be used to describe the construct of human system as a set of meanings generated in the continuous reciprocal interaction between different "domains" of meaning construction. This graphical representation is not created in order to explain what a human system "is" in terms of reality, but in order to explain the theoretical model (Nencini and Prati, 2010; Prati and Nencini, 2011).

According to this model, we can identify three main domains of meaning construction that contribute to the complex and reified meaning of a human system (Fig. 1).

The "cultural and ideological domain" refers to diffuse and deep-rooted forms of shared knowledge that are constituted by narratives that are available to everyone and that everyone can easily refer to when interacting with others (Bruner, 1991; Hammack, 2008; László, 2008). This domain of meaning construction can be imagined as constituted by widespread values, ethics and ideologies disseminated in the specific context of the human system. Various authors have contributed to the development of theories regarding widely diffused narratives. The Theory of Master Narratives (Hammack, 2008) describes how narratives constitute these forms of knowledge. Master narratives can be described as "a collective storyline which group members perceive as compulsory-a story which is so central to the group's existence and 'essence' that it commands identification and integration into the personal narrative" (Hammack, 2011). Examples of these master narratives can be found in social categories, such as gender, race and nationality (Hammack, 2006). 


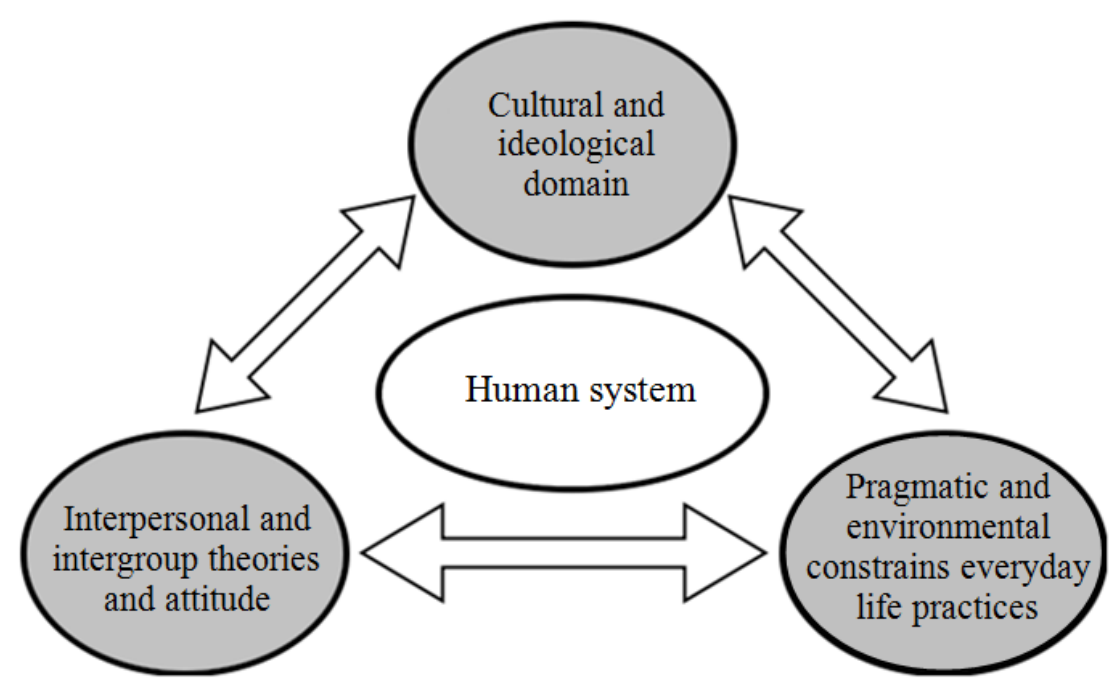

Fig. 1. Human system as socially constructed reality

Master narratives are continuously shaped as individuals interact and make decisions about which aspects of them to appropriate and which to repudiate (Hammack, 2011). Rappaport (2000) described "Dominant cultural narratives" as "over learned stories communicated through mass media or other large social and cultural institutions and social networks" (Rappaport, 2000). The dominant cultural narratives are known by most people in a culture. The author specifies these narratives both as direct and coded as visual images, as symbols, as stereotypes and as ritualized performances of behaviour (Rappaport, 2000).

The "domain of interpersonal and intergroup theories" is represented by theories that guide each individual to act contextually towards the human system and towards others in order to interpret and explain what is happening. Theories pertaining to this domain build their assumptions within the cultural domain described above and run as explanatory anchoring for the behaviour and the organizational functioning. Several theories have described the connection between cultural and social forms of contextual knowledge and behaviour: Moscovici, since his earlier formulations, defined social representations as "the elaboration of a social object by the community for the purpose of behaving and communicating" (Moscovici, 1963). Further developments of the Social Representations Theory extended the conceptualization linking representations and behaviour (Wagner, 1994), as Doise's contribution identified four levels in social psychology: Intrapersonal, interpersonal, intragroup and intergroup (Doise and Mapstone, 1986).

Interpersonal and intergroup theories constitute the representation that each individual has regarding his/her role within the human system (such as a professional role within an organization), as well as regarding the others in terms of groups and in terms of individuals (Prati and Nencini, 2011).

According to the adopted epistemological framework, social factors involved in a human system may structure meaning through the way in which they reconstruct various forms of scientific knowledge into social representations and personal theories. In this sense, scientific formalizations of knowledge are not to be intended as concrete pictures of specific organizational or psychological aspects (e.g., how the role of the perfect leader should work), or methodological praxis (e.g., how to operate within organizations). Instead, they can be used as forms of knowledge that can guide the change facilitator in his/her approach to the explicit reconstruction of the human system's meaning. Formalized scientific theories provide sources of comparison between possible narratives describing peculiar forms of human systems and offer insights of interventions that generated changes in other contexts.

Some of these theories can be particularly useful in our domain of intervention. For example, leadership theories are often relevant in organizational contexts for their circular power of describing and providing effective forms of interaction (Avolio et al., 2009; Dachler and Hosking, 1995; Zacko-Smith, 2007). Other relevant examples are constituted by theories describing emotions in organizations (Coupland et al., 2008) or descriptive and prescriptive stereotypes of gender in organizations (Heilman, 2012).

Finally, the domain of "practices and pragmatic constrains" refers to the way in which environmental constraints, actions and practices give meaning to their environments, thus contributing to particular constructions of situated meaning. At this level, which is characterized for being more contextual and pragmatic compared to the previous ones, the focus is on concrete 
elements of the environment (such as the peculiar elements of a workplace or of a room), pragmatic elements that reify roles and interactions (for example, the use of a white coat and a stethoscope by the medical staff in a hospital), or specific procedure and documents (such as the use of badges to record attendance in a workplace or formalized regular meetings among managers in an organization). The contribution of practices and pragmatic constrains, although apparently less evident than other sources of meaning construction, is strongly involved in structuring the meaning of a particular human system in a specific environment and a specific situation (Prati and Nencini, 2011).

As in the interpersonal and intergroup domain, several authors in the field of environmental psychology have developed significant contributions to this topic, creating scientific formalizations of the reality of practices. For example, Twigger-Ross and Uzzell (1996) described how environment contributes to maintenance and development of identity processes, while Gustafson (2001) developed a three interrelated poles model of self, others and environment, explaining the way in which meanings are attributed to places. Considering specifically the organizational human system, several researchers in the ergonomics field have inquired the connections between characteristics of the workplace and occupational health (Fairbrother and Warn, 2003; Leather et al., 1998). Once again, scientific knowledge is performatively used here in order to frame and share what can be observed in a particular human system, while collecting personal theories and practices by different social actors regarding their perception of their environment.

According to these assumptions, we stress how the GENERATIVE method considers human systems as symbolic unities, confined by the meaning given by people to them. As the three domains of meaning construction are continuously redefining and modifying their contents, the way the change facilitator enters and intervenes with the human system has to be defined according to the way the human system itself is configured in that specific moment. In other words, the change facilitator becomes part of the interactive process of meaning construction and contributes to generate peculiar meaning to the whole system during the intervention. As a consequence, he or she is not in a "neutral" position and should be aware that could not be considered exclusively as a "bringer of truth" or the "medicine to the disease" (Cassell and Symon, 2004; Denzin and Lincoln, 2000; Gergen, 1999).

A second consequence of the theoretical assumption described above is that problems are not "objective entities", intended as deviations from a normal situation or located inside the mind of individuals, but rather they can be framed as inefficient constructions of reality.
Since problems and human systems are considered to be socially constructed, interventions cannot be carried out as series of "best practices" whose efficacy can be considered independently from the context. They need to be carried out according to the specific meaning of that particular human system. In this vein, the change facilitator's role is to mediate between different possible forms of meaning and to promote alternative and more effective, constructions of shared meaning.

\section{Methodological Implications: A Proposal of Operating Practice}

The GENERATIVE method stands as a comprehensive tool for analyzing and dealing with various social realities. The methodology of intervention is directly derived from the theoretical framework depicted above.

Before entering into the details of the proposed methodological stages, a few assumptions concerning what we mean with the term "intervention" and about the position of the professional in the process of change need to be clarified.

Consistently with the socio-constructionist approach that holds the GENERATIVE method, the very nature of the "intervention" can be assimilated to a peculiar form of interaction, characterized by specific assumptions and social expectations in terms of roles, "stage" and "plot" (Goffman, 1959), in which the professional "enters" the context-target and becomes another element that interact within the system to generate its meaning (Denzin and Lincoln, 2000). In other words, the intervention cannot be summarized in the positivist metaphor of a direct and intentional action of a "content-expert" who knows what is needed in that particular social system, but rather it includes all the interactions that the "process-expert" professional facilitates in order to promote a change which is recursively negotiated with the social system (Contarello et al., 2013; Czarniawska, 2001).

Consequently, the intervention begins in the moment in which the change facilitator starts interacting with a particular human system.

According to Goffman (1959), meaning construction is both shaped and constrained by social roles and expectations. As a consequence the very first "action" of the change facilitator is to ensure the sharing of the meaning of the intervention itself within all the key persons composing the system. This also implies that the change facilitator should be ready to evaluate the absence of this shared adherence to the meaning of the intervention and act consequently. This is not a mere matter of changing the name of things, but it is the necessary attention that is required in order not to fall in a contradiction, that is affirming that reality is socially generated independently from the observer. As stressed 
before, the change facilitator is neither neutral nor transparent: His/her presence is already an action which perturbs the social system (Contarello et al., 2013). This is why it is important that the professional orients his or her competences in order to use his/her presence to promote a change in the direction that has been negotiated, rather than to unconsciously participate in the system's continuous movements.

To summarize this introduction to the methodological assumptions of a potential intervention with a social system, we stress that, since each action generates meaning, it is important to keep attention on the implications of an intervention on a double level: On the "meta-theoretical" level, concerning the direction of the change that may be produced in interaction with the system; on the "pragmaxtical" level, regarding the practical implications of every concrete action for the "meta-theoretical" level.

For this purpose, our methodological proposal can be divided into three stages: The first, which we call "system analysis"; the second, which is characterized by recursively renegotiations and redefinitions based on the "results" of the first stage; and the third, which is commonly associated to a stereotypical "intervention", characterized by actions and activities guided by the professional (Fig. 2). Because these three stages are largely overlapped and their sequential development is actually circular, it is difficult (and not really useful) to clearly affirm which stage that a particular action belongs to. Nevertheless, for expositive purposes, we present here the core elements of each methodological stage.

\section{The System Analysis}

On the "pragmatic" level, the system analysis is proposed as an integrated set of actions aimed to (a) investigate how all the individuals who interact within the system contribute to generate meaning about the system itself and (b) identify needs, resources and critical elements in the system. The major goal at this level is to report to the system a sort of "picture" of its functioning, by reifying some characteristics in order to orient and anticipate the possibility of change.

When framing the theoretical and methodological aspects of an intervention, it is worth noting that the source of the request of an intervention is usually a representative of the social system at stake or one "privileged" member of it and not the system as a whole. This is crucial because it guides the next spectrum of choices that are available for the change facilitator, from the type of needs and requests that will be addressed to the type of restitution that will be proposed. This is not to say that the system representative's requests have to guide the professional's intervention, but that the peculiar perspective of the privileged interlocutor provide a powerful representation of the social system which needs to be considered when planning the future communications and activities with the social system.

The process of "system analysis" has another indirect advantage: It allows all the social actors to participate in a consensual process of change, which explicitly relies on their resources and competences.

From the methodological point of view, the system analysis is largely derived from the Grounded Theory tradition (Charmaz, 1995; Glaser and Strauss, 1967), which aims to reconstruct a social reality by creating theoretical categories from the data collected on a specific field and then analyzing the relationships between key categories (Charmaz, 1990). Given the bottom-up approach to data collection and analysis, the system analysis inevitably produces situated, specific and context-related theories. This constructionist approach offers a flexible mean of exploring both fluid interactive processes and more stable social structures (Charmaz, 1990).

In line with the theoretical assumptions of the GENERATIVE method, the system analysis aims to reconstruct the complex matrix of interactions that give meaning to the social system by investigating the contents and narratives on the three domains (ideological, intergroup theories, environmental constrains). To this purpose, two forms of contents are investigated: Shared artifacts and individuals accounts.

Shared artifacts are represented by formal documents, informal procedures and practices, as well as practical tools that are used in the system to carry on everyday activities. This information mainly covers the "environmental constrain" domain of meaning construction.

Individuals who participate and act in relation to the system are invited to provide their views concerning the other two major domains of meaning construction. This is usually carried out by means of individual interviews and focus group discussions. Although we invite the reader to refer to other publications in order to deepen these two research tools (such as Cassell and Symon, 2004), a few recommendations on the way they are used in the system analysis can be useful.

First, although there is no mandatory procedure on this regard, individual interviews are preferably conducted before a focus group discussion. This is because in this way we favor a free and open discussion on the personal accounts and theories of the participants, limiting their potential embarrassment or difficulty in expressing negative or critical positions about the system (e.g., asking an employee's opinion on his/her department and/or its Head) that could possibly influence the individual interview if done afterwards. 


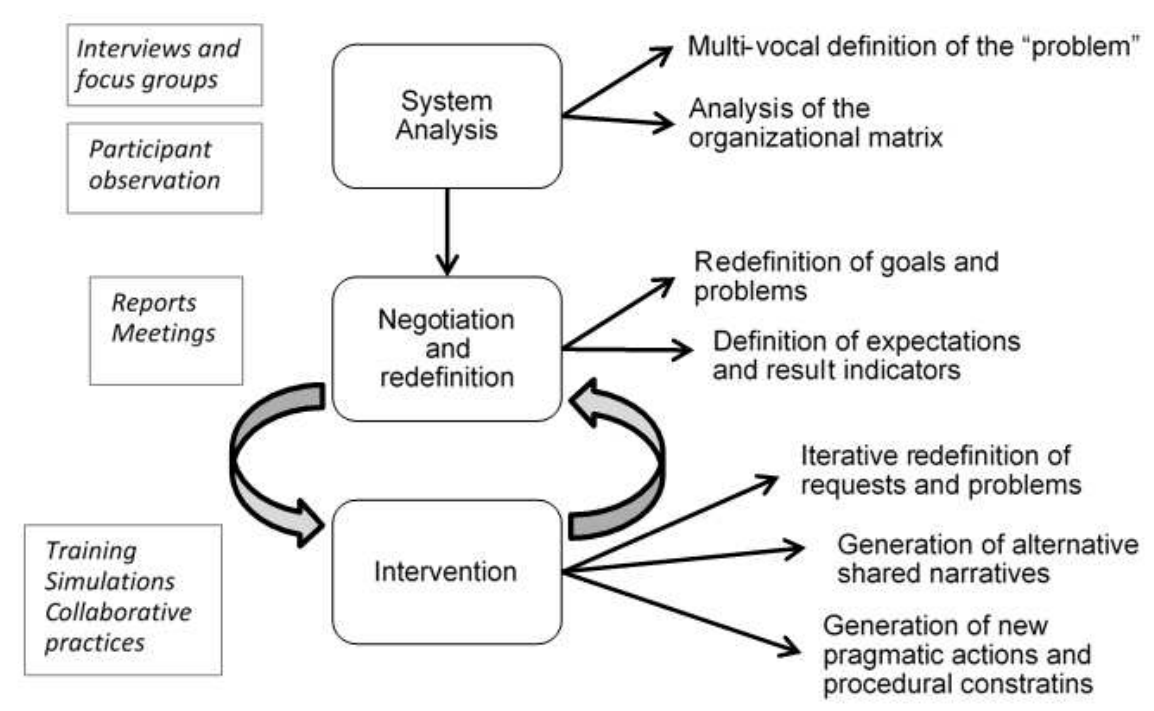

Fig. 2. Methodological steps of the GENERATIVE method (center), detailed description of each step (right) and examples of possible practices that can be implemented (left)

Second, although subdued to the specific requests expressed by the system (or its representatives) about the aims of the system analysis, interviews should cover the main areas which will allow to reconstruct the complex matrix of the system. This means to investigate (mainly, but not only) (a) the social actor's perception of the resources in the system, as well as of its main critical elements or areas that may be improved; (b) the social actor's involvement in the decision making of the system (or part of it); (c) the social actor's awareness of his/her role within the system and its relationship with other relevant roles; (d) the social actor's representation of the whole system, its core values or mission (particularly if it is an organization) and vision for the future; (e) the social actor's personal story within the system.

In line with the recursive and circular process of data collection, analysis, hypothesis formulation and recollection of data typical of the grounded methodology (Charmaz, 1995; Cicognani, 2002), personal accounts and documental information are used to reconstruct a first representation of the social system and its dynamics. This first representation is necessary in order to formulate preliminary hypotheses about the main resources available in the system, the main critical elements reported and from which perspective (i.e., how the different individuals position themselves regarding the "problem" on the basis of their roles) and the main narratives that hold the whole social system in terms of what can be done and what must not be done, what is valuable and what is not, etc.

Focus group discussions are usually used to report the first considerations collected during interviews and analysis of documents and to observe how individuals actually interact and discuss in relation to the core elements of their social system (Marková et al., 2007; Morgan, 1988). Focus group discussions are particularly useful in order to triangulate the various contents concerning the key narratives of the human system (i.e., to combine different views about the human system provided from various social actors' perspectives) and to observe how different social actors take position about these narratives. Focus groups also constitute an opportunity to verify with the social actors the initial "picture" of the human system that the change facilitator is reconstructing, thus functioning as a validity check of the system analysis that is taking place.

\section{Negotiation and Redefinition}

The outcome of the system analysis usually takes the form of a documental artefact, which typically is presented as an organized report that provides an overview of the system in terms of structure, roles, narratives, resources and (more importantly) main criticalities.

The report also offers the opportunity to share and negotiate both the goals and the methodology of the intervention with the representatives of the human system. The initial goals, those that drove the request of an intervention, are now redefined in the light of the structure and composition of the human system as derived from the system analysis. In this way, the privileged social actors and the change facilitator are brought to share a common direction, a common path and a common objective, which his explicitly declared and formalized in the report or other type of documentation.

The production of the system analysis report leads to a powerful strategic option in the hands of the change facilitator because it can be used as a reified tool, a 
"picture of reality", a sort of diagnosis which derives its effectiveness and legitimation from the medical model while never abdicating a theoretical coherence with the epistemological premises.

Formally the phase of negotiation and redefinition is already (as the system analysis itself) a phase of performative intervention. By presenting a "picture" of reality, the change facilitator deals with the laypeople's expectation of a sort of cause-and-effect approach, while bringing all the social actors together in an active interaction aimed to define the meaning of that reality which also gives the consultant the opportunity to redefine, re-configure and re-narrate some of its critical components. This process usually addresses goals, problems and the actual actions of the intervention but also the concrete indicators of the expected change.

The process of explicit identification of indicators of change is particularly important because it anticipates concrete and observable (often, measurable) elements that provide and share with the human system the quality and quantity of change. At the same time, the very same activity of anticipating the indicators of change with the social actors makes the change not only possible, but already ongoing, thus facilitating it.

This operation of co-construction and redefinition of meaning is the core action of the intervention, moreover it is the more theoretically embedded action in the hands of the change facilitator because it opens the ground for an actual meaning negotiation with the involved actors on the key dimensions of the interpersonal and intergroup theories (Fig. 1). There is no preset or predetermined protocol for this operation precisely because there is no configuration of reality valid "per se". More appropriately, the goal of the change facilitator is to reduce the gap in the set of meanings held by the actors regarding the fundamental goals of the system, their role and the rules regulating the interactions within the system.

In terms of practices, the main tool for this phase is made of a set of restitution and intervention planning meetings with the main actors, on the basis of the system analysis report. During the conduction of these meetings, a set of alternative configurations are proposed to the actors in order to engage them in the discussion on the design of the system matrix and the roles that sustain it.

\section{The Intervention}

After having generated a common view on the goals that have to be pursed and the main strategies through which they can be achieved, the "intervention" may be implemented. We separate this set of actions from the rest of activities described above (i.e., the system analysis and the negotiation and redefinition) because this is what the system representatives usually expect and demand. However, in line with the constructionist assumptions of the GENERATIVE method, the process of change starts in the very moment in which the system analysis generates alternative constructions of meaning and calls all the social actors to take into consideration multiple perspectives as compared with the one initially declared.

At this stage therefore, a series of actions may be planned with the aim of working on a double level: First, to maintain the collaborative participation of the social actors in order to construct an intervention which has meaning for them and that thus allows them to generate change within their human system, second, to generate new narratives that may substitute or be put beside those generating the "problem", multiplying the alternatives available for each social actor and to create new pragmatic tools (e.g., new meetings, new roles, new teams) or procedural constrains (documents, forms, check lists, procedures).

On the first level, any kind of interactive activity that may involve social actors who occupy key roles in the system is helpful in strengthening a perception of collaboration and active participation. The generation of such an interactive framework among social actors and change facilitator is crucial in order to produce an overall change in the system.

On the second level, change facilitator and social actors are engaged in the creative process of widening the spectrum of what exists and generating alternatives to the dysfunctional configuration of the "problem". The specific content of each intervention may vary from situation to situation, but some examples of commonly used interactive activities are: Training courses, role playing (Greenberg and Eskew, 1993), simulations (Keys and Wolfe, 1990), collaborative practices (Gergen, 2006; Karakas, 2009), group problem solving (Chiu, 2000; Paulus and Nijstad, 2003). Of course, this list could be extended, but it is worth noting that the key factor is represented by a strategic and pragmatic approach to the generative process of effective alternatives rather than the application of a particular technique. Here, situational creativeness is much more functional than any a priori knowledge.

During the formal intervention, which is directed to pursue the shared goals formalized in the report, the initial system analysis is compared with the new or changing meaning that is generated. The overall result is a circular process of continuous investigation and modification which generates new configurations of the system (Fig. 2).

\section{Conclusion}

The present paper aims to describe the theoretical framework and the methodological practices of the GENERATIVE method, which was created to provide a guideline for those who aim to promote an effective 
change in a human system. According to the constructionist approach that sustains the model, we can identify four key features that are particularly relevant for a proper and effective implementation of the GENERATIVE method.

First, a human system is configured as a socially constructed reality, forged by deeply rooted narratives circulating in the cultural context but at the same time recursively generated through the interaction between roles, in terms of interpersonal theories and practices. This means that every "voice" in the human system contributes to its creation, from the top manager to the employee (but also the customer) in a company, or a doctor and a patient in a health institution. Thus, the intervention is not aimed to remove problems, but to generate new effective narratives.

Second, the GENERATIVE method is focused on the collaboration between the change facilitator and the social factors involved in the human system. The collaboration does not merely mean the consensus between roles or agreement on what has to be done through the intervention, but it aims to construct a new reality whose meaning-in order to be significant-should be jointly generated by all the roles of the human system. This allows to produce change which can be configured as shared by all the participants and not undergone.

Third, the role of the change facilitator has to be considered as another reality configured by the whole human system. This means that the change facilitator, as a part of the human system, is never in a neutral position.

Fourth, the GENERATIVE method shapes the intervention as a recursive process: The intervention is not considered as a series of context-independent best practices, but as locally co-constructed and goaloriented. The overall intervention is the result of a series of performative tools (coaching, training, role playing, etc...) whose purpose is continuously linked to the negotiation and generation of the human system reality.

Jointly considering the methodological approach and its link to the epistemological and theoretical framework, we consider the GENERATIVE as an effective, social based methodology to promote change in contexts involving human interactions.

\section{Acknowledgment}

The authors want to thank Mathilda Tassinari Rogalin for linguistic revisions of the paper.

\section{Author's Contributions}

Alessio Nencini: The author has participated in the conception and design of the paper, with particular attention to the definition of the theoretical model. He has also contributed to the writing of the methodological section of the manuscript.
Alessandro Meneghini: The author has contributed to the drafting of the paper and for what concerns the writing of the theoretical section. The author has contributed reviewing the article jointly with the other authors.

Marco Prati: The author has participated in the conception of the paper and in the definition of the theoretical model. He has also contributed to the writing of the manuscript.

\section{References}

Avolio, B.J., F.O. Walumbwa and T.J. Weber, 2009. Leadership: Current theories, research and future directions. Ann. Rev. Psychol., 60: 421-49. DOI: 10.1146/annurev.psych.60.110707.163621

Berger, P.L. and T. Luckmann, 1967. The Social Construction of Reality. 1st Edn., Penguin, Harmondsworth, ISBN-10: 0385058985, pp: 219.

Blumer, H., 1969. Symbolic Interactionism. 1st Edn., University of California Press, Berkeley, CA.

Bruner, J., 1991. The narrative construction of reality. Critical Inquiry, 18: 1-21. DOI: 10.1086/448619

Burr, V., 1998. Overview: Realism, Relativism, Social Constructionism and Discourse. In: Social Constructionism, Discourse and Realism, Parker, I. (Ed.), Sage Publications, London, ISBN: 9780761953777, pp: 13-26.

Cassell, C. and G. Symon, 2004. Essential Guide to Qualitative Methods in Organizational Research. 1st Edn., Sage, London, ISBN-10: 0761948872, pp: 388.

Charmaz, K., 1990. 'Discovering' chronic illness: using grounded theory. Soc. Sci. Med., 30: 1161-1172. DOI: 10.1016/0277-9536(90)90256-R

Charmaz, K., 1995. Grounded Theory. In: Rethinking Methods in Psychology, Smith, J.A., R. Harré and L. van Langenhove (Eds.), Sage, London, pp: 27-49.

Chiu, M.M., 2000. Group problem-solving processes: Social interactions and individual actions. J. Theory Soc. Behav., 30: 27-49.

DOI: $10.1111 / 1468-5914.00118$

Cicognani, E., 2002. L'approccio Qualitativo Della Grounded Theory in Psicologia Sociale: Potenzialità, Ambiti di Applicazione e Limiti. In: Metodi Qualitativi in Psicologia Sociale, Mazzara, B.M. (Ed.), Carocci, Roma, pp: 43-59.

Contarello, A., R. Cancian, M. Sarrica and A. Nencini, 2009. Il dolore come rappresentazione condivisa: Indagine con operatori della salute all'interno del progetto della regione Veneto "Ospedale e territorio senza dolore". Psicol. Della Salute, 2: 27-49.

DOI: 10.3280/PDS2009-002003 
Contarello, A., D. Romaioli, A. Nencini and S. Brondi, 2013. Pensare e fare 'con'. Rilevanza sociale e ricerca sociopsicologica ovvero metodologie e pratiche per una ricerca sociocostruttivista. Psicol. Soc., 8: 41-66.

Coupland, C., A.D. Brown, K. Daniels and M. Humphreys, 2008. Saying it with feeling: Analysing speakable emotions. Human Relat., 61: 327-353. DOI: $10.1177 / 0018726708088997$

Czarniawska, B., 2001. Is it possible to be a constructionist consultant? Manage. Learn., 32: 253-266. DOI: $10.1177 / 1350507601322006$

Dachler, H.P. and D. Hosking, 1995. The Primacy of Relations in Socially Constructing Organizational Realities. In: Management and Organization: Relational Alternatives to Individualism, Hosking, D., H.P. Dachler and K.J. Gergen (Eds.), Avebury/Ashgate Publishing, Brookfield, VT., pp: 1-28.

Denzin, N.K. and Y.S. Lincoln, 2000. The Discipline and Practice of Qualitative Research. In: Handbook of Qualitative Research, Denzin, N.K. and Y.S. Lincoln (Eds.), Sage, Thousand Oaks, CA., pp: 1-32.

Doise, W. and E. Mapstone, 1986. Levels of Explanation in Social Psychology. 1st Edn., Cambridge University Press, Cambridge, ISBN-10: 0521307481, pp: 194.

Fairbrother, K. and J. Warn, 2003. Workplace dimensions, stress and job satisfaction. J. Managerial Psychol., 18: 8-21.

DOI: $10.1108 / 02683940310459565$

Flick, U., 1998. The social construction of individual and public health: Contributions of social representations theory to a social science of health. Soc. Sci. Inform., 37: 639-662. DOI: $10.1177 / 053901898037004005$

Flick, U., 2000. Qualitative inquiries into social representations of health. J. Health Psychol., 5: 315-324. DOI: 10.1177/135910530000500303

Gergen, K.J., 1973. Social psychology as history. J. Personality Soc. Psychol., 26: 309-320. DOI: $10.1037 / \mathrm{h} 0034436$

Gergen, K.J., 1997. On the poly/tics of postmodern psychology. Theory Psychol., 7: 31-36. DOI: $10.1177 / 0959354397071003$

Gergen, K.J., 1999. An Invitation to Social Construction. 1st Edn., SAGE, London, ISBN-10: 080398376X, pp: 256.

Gergen, K.J., 2006. Theory in action. Theory Psychol., 16: 299-309. DOI: 10.1177/0959354306064278

Gergen, K.J., 2009. Relational Being: Beyond Self and Community. 1st Edn., Oxford University Press, New York, ISBN-10: 0199719403, pp: 448.
Gergen, K.J., 2011. Relational being: A brief introduction. J. Constr. Psychol., 24: 280-282. DOI: $10.1080 / 10720537.2011 .593453$

Gergen, K.J. and T.J. Thatchenkery, 2004. Organization science as social construction: Postmodern potentials. J. Applied Behav. Sci., 40: 228-249. DOI: $10.1177 / 0021886304263860$

Gergen, K.J., M.M. Gergen and F.J. Barrett, 2004. Dialogue: Life and Death of the Organization. In: Handbook of Organizational Discourse, Grant, D., C. Hardy, C. Oswick (Eds.), Sage, Thousand Oaks, CA., pp: 39-59.

Glaser, B.G. and A.L. Strauss, 1967. The Discovery of Grounded Theory: Strategies for Qualitative Research. 1st Edn., Aldine, Chicago, ISBN-10: 0202302601, pp: 271.

Goffman, E., 1959. The Presentation of Self in Everyday Life. 1st Edn., Doubleday, New York, ISBN-10: 0385094027, pp: 259.

Greenberg, J. and D.E. Eskew, 1993. The role of role playing in organizational research. J. Manage., 19: 221-241. DOI: 10.1177/014920639301900203

Gustafson, P., 2001. Meanings of place: Everyday experience and theoretical conceptualizations. J. Environ. Psychol., 21: 5-16. DOI: $10.1006 /$ jevp.2000.0185

Hammack, P.L., 2006. Identity, conflict and coexistence: Life stories of Israeli and Palestinian adolescents. J. Adolescent Res., 21: 323-369. DOI: $10.1177 / 0743558406289745$

Hammack, P.L., 2008. Narrative and the cultural psychology of identity. Personality Soc. Psychol. Rev., 12: 222-247. DOI: $10.1177 / 1088868308316892$

Hammack, P.L., 2011. Narrative and the politics of meaning. Narrat. Inquiry, 21: 311-318. DOI: 10.1075/ni.21.2.09ham

Heilman, M.E., 2012. Gender stereotypes and workplace bias. Res. Organiz. Behav., 32: 113-135. DOI: $10.1016 /$ j.riob.2012.11.003

Henwood, K.L. and N.F. Pidgeon, 1992. Qualitative research and psychological theorizing. Brit. J. Psychol., 83: 97-111.

Johnson, P. and C. Cassell, 2001. Epistemology and work psychology: New agendas. J. Occupat. Organiz. Psychol., 74: 125-143. DOI: $10.1348 / 096317901167280$

Kashima, Y., 2014. Meaning, grounding and the construction of social reality. Asian J. Soc. Psychol., 17: 81-95. DOI: 10.1111/ajsp.12051

Karakas, F., 2009. New paradigms in organization development: Positivity, spirituality and complexity. Organiz. Dev. J., 27: 11-26. 
Kegan, R. and L.L. Lahey, 2001. How the Way we Talk can Change the Way we Work. 1st Edn., JosseyBass, San Francisco, CA., ISBN-10: 0787958662, pp: 256.

Keys, B. and J. Wolfe, 1990. The role of management games and simulations in education and research. J. Manage., 16: 307-336. DOI: $10.1177 / 014920639001600205$

László, J., 2008. The Science of Stories: An Introduction to Narrative Psychology. 1st Edn., Routledge, ISBN-10: 0415457947, pp: 240.

Leather, P., M. Pyrgas, D. Beale and C. Lawrence, 1998. Windows in the workplace: Sunlight, view and occupational stress. Environ. Behav., 30: 739-762. DOI: $10.1177 / 001391659803000601$

Marková, I., P. Linell, M. Grossen, 2007. Dialogue in Focus Groups: Exploring Socially Shared Knowledge. 1st Edn., Equinox, London, ISBN-10: 1845530500, pp: 243.

Mead, G.H., 1934. Mind, Self and Society: From the Standpoint of a Social Behaviorist. 1st Edn., Chicago University Press, Chicago, pp: 400.

Morgan, D.L., 1988. Focus Group as Qualitative Research. 1st Edn., Sage, Newbury Park, CA.

Moscovici, S., 1963. Attitudes and opinions. Ann. Rev. Psychol., 14: 231-260.

DOI: 10.1146/annurev.ps.14.020163.001311

Nencini, A. and M. Prati, 2010. Processi di costruzione del ruolo professionale in contesti interculturali. L'intervento rivolto al middle-management del St. Mary's Hospital Lacor di Gulu (Uganda). Scienze dell'Interazione, 2: 51-56.

Paulus, P.B. and B.A. Nijstad, 2003. Group Creativity: Innovation through Collaboration. 1st Edn., Oxford University Press, New York, ISBN-10: 0195147308, pp: 368 .
Perren, L. and P. Grant, 2000. The evolution of management accounting routines in small businesses: A social construction perspective. Manage. Account. Res., 11: 391-411.

DOI: $10.1006 /$ mare 2000.0141

Prati, M. and A. Nencini, 2011. How can organizational psychology contribute to international cooperation projects? The case of Lacor hospital in Gulu (Uganda). Proceedings of the Congresso Nazionale CUCS sulla Cooperazione Universitaria, Sept. 15-16, Padova,

Rappaport, J., 2000. Community narratives: Tales of terror and joy. Am. J. Community Psychol., 28: 1-24. DOI: $10.1023 / \mathrm{A}: 1005161528817$

Sugiman, T., K.J. Gergen, W. Wagner and Y. Yamada, 2008. The Social Turn in the Science of Human Action. In: Meaning in Action: Constructions, Narratives and Representations, Sugiman, T., K. Gergen, W. Wagner and Y. Yamada (Eds.), Springer, New York, pp: 1-20.

Twigger-Ross, C. and D. Uzzell, 1996. Place and identity processes. J. Environ. Psychol., 16: 205-220. DOI: $10.1006 /$ jevp.1996.0017

Wagner, W., 1994. The fallacy of misplaced intentionality in social representation research. J. Theory Soc. Behav., 24: 243-165. DOI: $10.1111 / \mathrm{j} .1468-5914.1994 . t b 00255 . \mathrm{x}$

Wagner, W. and J. László, 2003. Theories and Controversies in Societal Psychology. 1st Edn., New Mandate, Budapest, ISBN-10: 9639494291 , pp: 212.

Zacko-Smith, J., 2007. The leader label: Influencing perceptions, reality and practice. Leadership Rev., 7: 75-88. 